Molekularbiologie der Zelle I., Deutsches Krebsforschungszentrum (DKFZ), Im Neuenheimer Feld 280, D-69120, Heidelberg Germany. e-mail: g.schuetz@dkfzheidelberg.de

Received 27 July 2001; accepted 29 October 2001.

E. Casanova, T. Lemberger, S. Fehsenfeld, E. Greiner, A.F. Stewart ${ }^{1}$, and G. Schütz Deutsches

Krebsforschungszentrum (DKFZ)

${ }^{1}$ European Molecular

Biology Laboratory (EMBL) Heidelberg, Germany

\section{One-Step RT-PCR for Screening Microdissected Tissue Samples}

BioTechniques 32:242-248 (February 2002)

The technology of laser-capture microdissection (LCM) enables the easy extraction of single cells or defined groups of cells from a tissue section $(1,2)$. This technique uses a laser pulse to activate a plastic polymer, which binds to and captures cells from a frozen or paraffin-embedded tissue section. Captured cells present on this solid support can then be used for nucleic acid and/or protein analysis. This technology is becoming increasingly important for the characterization of molecular profiles of cell subpopulations within a heterogeneous tissue (4).

Despite the enormous power of LCM technology, a constant challenge for investigators has been the consistent manipulation of small quantities of material. Most protocols require an amplification step, preceded by multistep procedures to isolate and purify the molecular components (3). For example, the steps involved in gene expression studies using RT-PCR include microdissection, denaturation of RNA using guanidinium isothiocyanatebased reagents, phenol-chloroform treatment to remove proteins, precipitation of nucleic acids, washing, resuspension of RNA, re-extraction of RNA when required for increased purity, reverse transcription to produce cDNA, and PCR using gene-specific primers. Although this standard protocol is effective, RNA can potentially be lost at each step.

In this report, we describe a one-step protocol for screening gene expression in microdissected cells using RT-PCR. Significantly, this procedure does not require an initial isolation of RNA. Rather, the reverse transcription and subsequent PCR amplification of specific genes are conducted directly from the microdissected cells. This procedure is a rapid, specific, and cost-effective screening technique.

When we started this project, we hypothesized that, because of the small

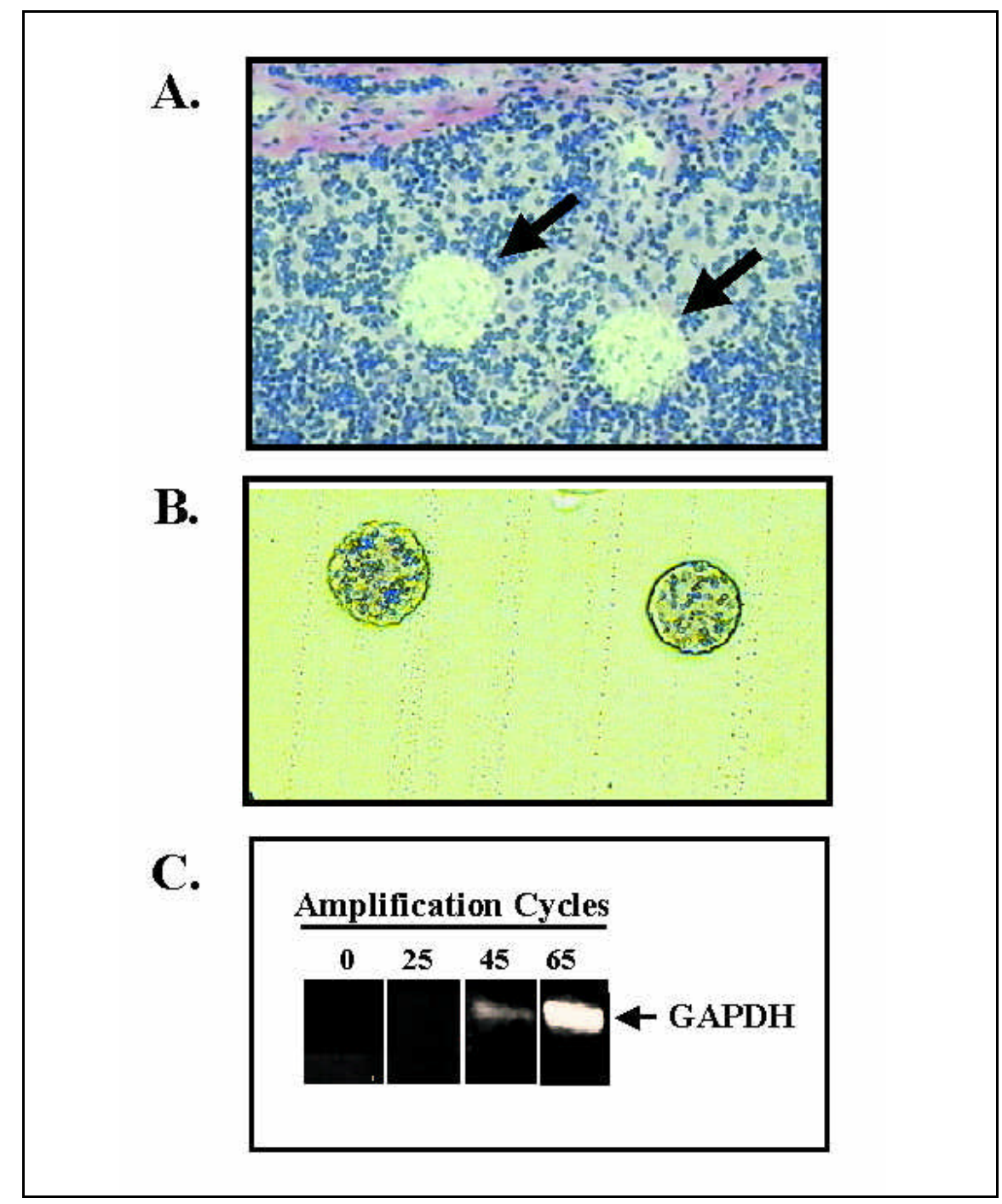

Figure 1. Microdissection and RT-PCR of cells from human remnant tonsil. In this representative image, the cells were microdissected from a frozen section of human tonsil, and the GAPDH was amplified using the one-step RT-PCR protocol. (A) Tonsil section from which two areas have been microdissected (arrow, 200× magnification). (B) Microdissected regions of tonsil (200× magnification). (C) Determination of optimal PCR cycles for amplifying the GAPDH from microdissected tonsil. Approximately 100 cells were microdissected from human tonsil and used for RT-PCR. GAPDH-specific primers were used to amplify for 25,45 , or 65 cycles. The GAPDH product ( $476 \mathrm{bp}$ ) was the only band present at all conditions. 
Table 1. Sequence of Primers Used in RT-PCR Experiments

\begin{tabular}{|c|c|c|}
\hline Gene & Primer Sequence $\left(5^{\prime} \rightarrow 3^{\prime}\right)$ & $\begin{array}{l}\text { Size of } \\
\text { Product (bp) }\end{array}$ \\
\hline GAPDH & $\begin{array}{l}\text { forward: TGCTGAGTATGTCCTGGACTCT } \\
\text { reverse:ATGTGATCATACTTGGGAGGTTTC }\end{array}$ & 476 \\
\hline PSA (7) & $\begin{array}{l}\text { Primary Primers } \\
\text { forward:TACCCACTGCATCAGGAACA } \\
\text { reverse: CCTTGAAGCACACCATTACA } \\
\text { Nested Primers } \\
\text { forward: ACACAGGCCAGGTATTTCAG } \\
\text { reverse: GTCCAGCGTCCAGCACACAG }\end{array}$ & 355 \\
\hline EMP2 & $\begin{array}{l}\text { forward: ATGTTGGTGCTTCTTGCTTTCATCATCGCC } \\
\text { reverse: CTATTTGCGCTTCCTCAGTATCAGGTAC }\end{array}$ & 502 \\
\hline PSMA (6) & $\begin{array}{l}\text { forward: AGGGGCCAAAGGAGTCATTCTCTACTCCGA } \\
\text { reverse: СTCTGCAATTCCACGCCTAT }\end{array}$ & 196 \\
\hline
\end{tabular}

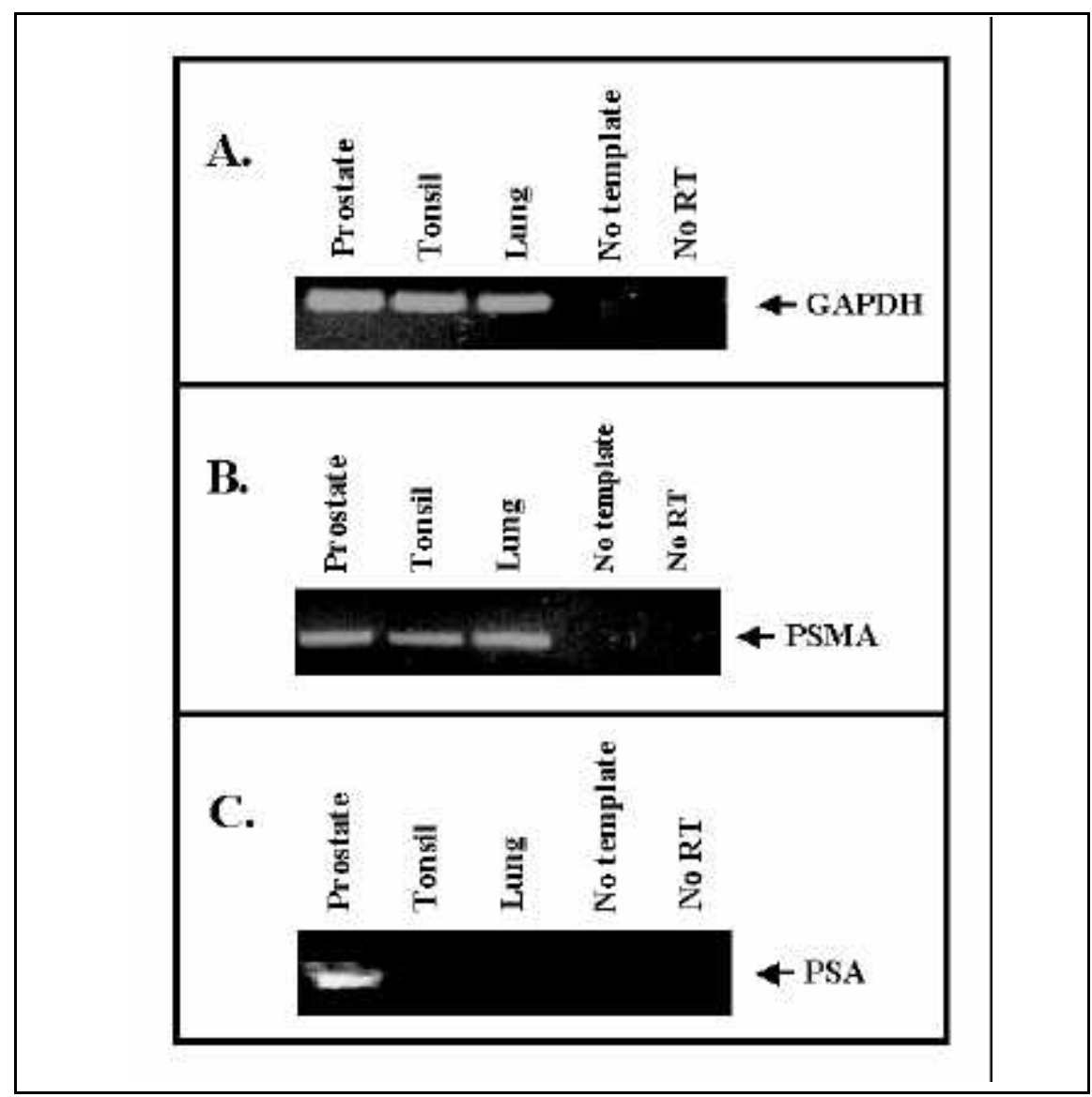

Figure 2. Amplification of GAPDH and PSMA from various microdissected tissue types. The cells were microdissected from human prostate, tonsil, and lung samples (using approximately 100, 250, and 250 epithelial cells, respectively) and directly used for single-step RT-PCR. Following cDNA synthesis, (A) GAPDH-specific, (B) PSMA-specific, or (C) PSA-specific primers were used for amplification. Note that both GAPDH (476 bp) and PSMA (196 bp) could be amplified from all three tissue types. PSMA amplification is consistent with the known expression pattern of this gene. Consistent with published results, PSA ( $355 \mathrm{bp}$ ) was only amplified from the prostate sample. Controls without cells (template) and without reverse transcriptase were negative. For all conditions, there were no extraneous products present on the gel. size of microdissected tissue, sufficient RNA would be accessible for cDNA synthesis directly from the cells without an initial RNA purification. Remnant human tissue samples were obtained from the UCLA Human Tissue Research Center (HTRC), following the acquisition of the appropriate human use approval. RT-PCR experiments were first conducted using tonsil samples (subsequent experiments used prostate, eye, and lung samples). The samples were kept at $4^{\circ} \mathrm{C}$ until they were embedded in Tissue Tek ${ }^{\circledR}$ O.C.T. Compound (Sakura Finetek USA, Torrance, CA, USA). The entire process of the surgical removal, examination by a pathologist, retrieval by the HTRC, and embedding in O.C.T. typically took $2 \mathrm{~h}$ or less.

Tissue samples in the O.C.T. compound were sectioned using a Microm HM505E cryostat. Between samples, the cryostat was thoroughly cleaned, and a new blade was used for each sample. These steps were taken to minimize contamination in subsequent reactions. Tissue sections $(10 \mu \mathrm{m})$ were placed on non-charged microscope slides (Fisher Scientific, Pittsburgh, PA, USA), dehydrated with $70 \%$ ethanol for $30 \mathrm{~s}$, and stained with hematoxylin then eosin, according to protocols established by the National Cancer Institute Cancer Genome Anatomy Project (http://cgap.nci.nih.gov). The samples were rinsed with increasing percentages of ethanol $(70 \%, 95 \%$, and $100 \%)$, followed by rinsing with xylenes for 10-15 min and then a second xylene rinse for $30 \mathrm{~min}$. All solutions were prepared fresh. When dilutions were required, double-distilled RNase-free water was used. The samples were air dried for 5-10 min and stored desiccated for no more than $1 \mathrm{~h}$ until microdissection was performed.

A Pixcell ${ }^{\circledR} 200$ Laser Capture Microdissection Microscope (Arcturus Engineering, Mountain View, CA, USA) was used for microdissection, following the manufacturer's instructions. The cells were captured on the CapSure ${ }^{\mathrm{TM}}$ LCM Transfer Film (Arcturus Engineering) using a spot size of $30 \mu \mathrm{m}$, an amplitude of $30 \mathrm{~mW}$, and a pulse of 0.5 ms. Approximately 250 cells were microdissected from this sample (Figure 1, A and B). A single-step RT-PCR was performed directly on the microdissect- 
ed cells. After capturing the cells, the plastic transfer film was carefully pealed off the CapSure LCM cap using a clean (RNase-free), sharp pair of tweezers. The film was put directly into a clean RNase-free tube containing the Ready-To-Go ${ }^{\text {TM }}$ RT-PCR Beads from Amersham Biosciences (Piscataway, NJ, USA). Identical results were obtained using the OneStep RT-PCR Kit (Qiagen, Valencia, CA, USA). The cDNA was prepared using primer $\operatorname{pd}(\mathrm{T})_{12-18}$, according to the manufacturer's instructions. Similar results were obtained using the $\operatorname{pd}(\mathrm{N})_{6}$ random oligonucleotides supplied with the Amersham Biosciences kit. The cDNA was synthesized at $42^{\circ} \mathrm{C}$ for $30 \mathrm{~min}$, followed by a 5 -min incubation at $95^{\circ} \mathrm{C}$ to inactivate the reverse transcriptase. Following cDNA synthesis, gene-specific primers were added (Table 1). All reac- tions were performed using a model 9700 thermal cycler (Perkin Elmer Life Science, Gaithersburg, MD, USA). The amplification consisted of up to $65 \mathrm{cy}$ cles of the following steps: denaturation at $95^{\circ} \mathrm{C}$ for $30 \mathrm{~s}$, annealing at $55^{\circ} \mathrm{C}$ for $30 \mathrm{~s}$, and extension at $72^{\circ} \mathrm{C}$ for $1 \mathrm{~min}$. At the end of the run, a final extension step was added at $72^{\circ} \mathrm{C}$ for $5 \mathrm{~min}$. PCR products $(25 \mu \mathrm{L})$ were electrophoresed on a $1 \%$ agarose gel containing 0.2 $\mu \mathrm{g} / \mathrm{mL}$ ethidium bromide. The bands were visualized using a Gel-Doc ${ }^{\mathrm{TM}}$ 1000 with Molecular Analyst ${ }^{\circledR}$ software (Bio-Rad Laboratories, Hercules, CA, USA). All experiments were repeated a minimum of three times. Figure 1C shows the one-step RT-PCR procedure using a poly(dT) oligonucleotide for cDNA synthesis, followed by addition of glyceraldehyde-3-phosphate dehydrogenase (GAPDH) primers for the

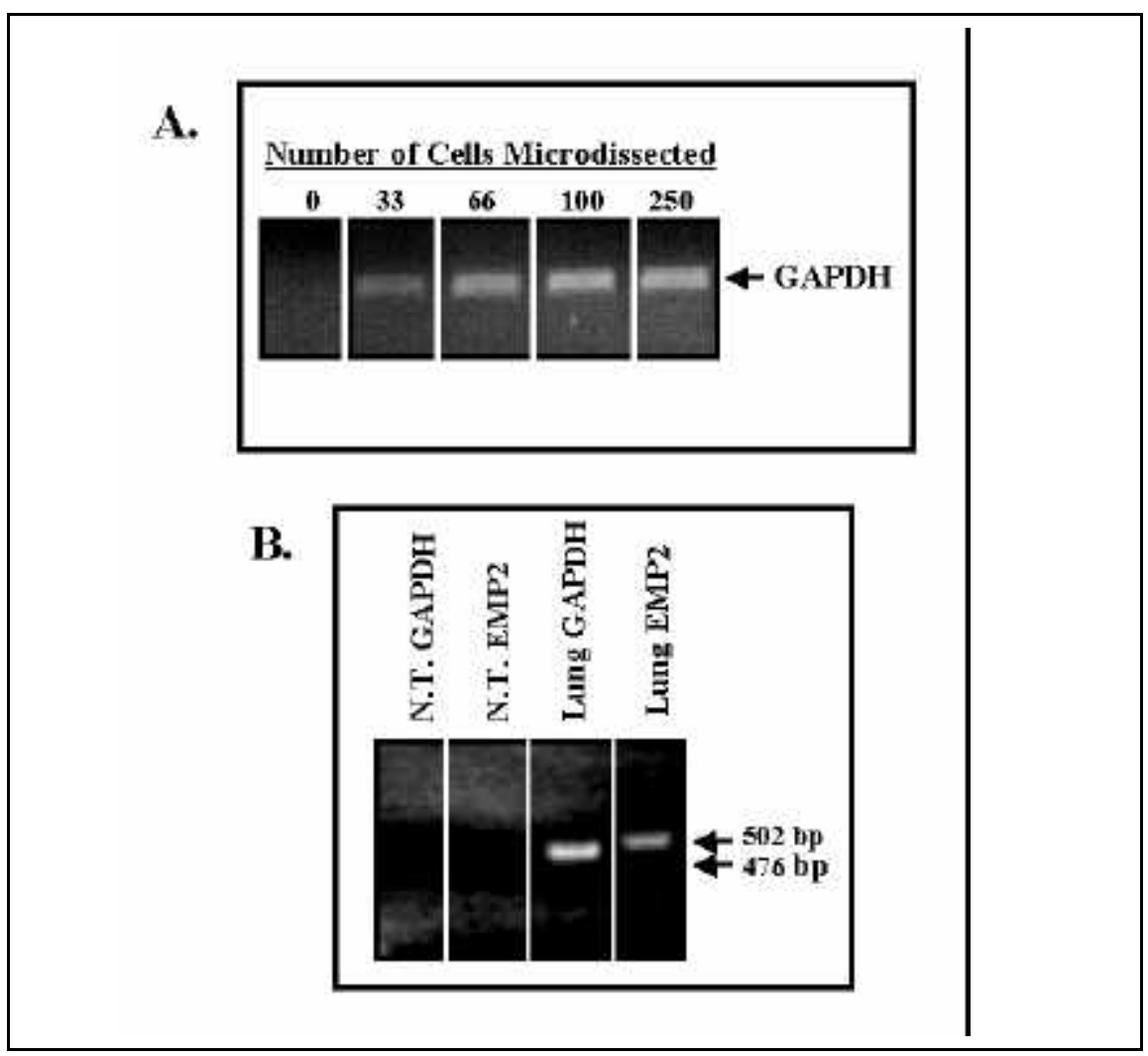

Figure 3. Amplification from different numbers of microdissected cells. (A) Approximately 33, 66, 100 , and 250 cells were microdissected from human tonsil. Following cDNA synthesis, GAPDH-specific primers were added, and amplification proceeded for 65 cycles. The GAPDH product was visualized using conventional gel electrophoresis from as few as 33 cells. (B) Approximately eight cells were microdissected from the alveolar wall of remnant human lung sections. Following cDNA synthesis, GAPDH-specific or EMP2-specific primers were added, and amplification proceeded for 65 cycles. Note that GAPDH and EMP2 expression can readily be detected from only eight microdissected cells. Controls without cells (no template, N.T.) and without reverse transcriptase were negative. For panels A and $\mathrm{B}$, there were no extraneous products present on the gel.

specific amplification of this cDNA by PCR. A weak 476-bp band was observed after 45 PCR cycles; this band was more intense after 65 amplification cycles. Notably, even after 65 cycles, only one product was detected. We were confident that the amplified product was specific for GAPDH cDNA and not caused by any residual genomic DNA because $(i)$ the primers span an intron (genomic DNA would thus have produced a significantly larger product) and (ii) no band was detected when this procedure was performed in the absence of reverse transcriptase (data not shown). In other experiments, the nucleic acid extraction from the gel, followed by DNA sequencing, confirmed the identity of this product (data not shown). This PCR product was not unique to this tissue sample because the GAPDH could be amplified from other tissues, such as human lung and prostate (Figure 2A). Furthermore, a non-housekeeping gene, prostate-specific membrane antigen (PSMA), could also be amplified from tonsil, lung, and prostate, which was consistent with previous reports (Figure 2B) (8).

We further tested the limits of sensitivity of this one-step procedure with regard to the number of microdissected cells required to obtain an RT-PCR signal. To do this, we varied the number of laser pulses used to captured the cells from a section of tonsil. For this tissue, 30-35 cells are captured with each laser pulse. As shown in Figure 3A, we tested the one-step RT-PCR screening protocol on the cells captured by 1,2 , 3 , and 8 laser pulses. A GAPDH-specific band was observed with as few as 30-35 cells (one laser pulse), and the intensity of the GAPDH PCR product increased with increasing cell number (Figure 3A). To examine whether this protocol could amplify product from even fewer cells, we microdissected lung epithelial cells. From as few as eight captured lung epithelial cells, we could specifically amplify GAPDH and epithelial membrane protein-2 (EMP2) (Figure 3B) (9).

To test the specificity of this one-step RT-PCR screening protocol, we examined the expression of prostate-specific antigen (PSA) in different tissues. One hundred cells were microdissected from human lung (epithelium), tonsil (lym- 
phocytes), or prostate (glandular epithelium) tissue. To improve sensitivity yet maintain specificity, a nested PCR was used. The samples were amplified for 50 cycles, as described earlier with a primary primer set. The primer reaction $(1 \mu \mathrm{L})$ was removed and amplified for an additional 45 cycles. Consistent with previous results, PSA was only detected in prostate and not in lung or tonsil tissue (Figure 2C) (10). Analogous results have been found with the specific amplification of $\beta$ B 1 crystallin from microdissected lens epithelia but not from optic nerve or sclera (data not shown). To date, all primer sets tested have yielded RT-PCR products. These have included GAPDH, PSA, PSMA, EMP2, $\beta$-actin (5) (not shown), and $\beta$ B1 crystallin (not shown).

Here, we describe a simple and rapid one-step RT-PCR protocol from laser-captured microdissected tissue. Notably, as a method for rapidly screening dissected cells for gene expression, this protocol has the advantage of decreased manipulation of the sample because no RNA extraction step is necessary. Because of this, the likelihood of losing RNA during this microisolation protocol is diminished. Currently, the technique described here is suitable for rapid screening of microdissected tissue samples but not quantitation. Nevertheless, this protocol demonstrates sensitivity (e.g., detecting signals from as few as $8-10$ cells) and specificity (e.g., detecting tissue-specific gene products). We anticipate that this assay can be adapted for a more quantitative approach when combined with real-time PCR technology.

\section{REFERENCES}

1.Bonner, R.F., M. Emmert-Buck, K. Cole, T. Pohida, R. Chuaqui, S. Goldstein, and L.A. Liotta. 1997. Laser capture microdissection: molecular analysis of tissue. Science 278:1481-1483.

2.Emmert-Buck, M.R., R.F. Bonner, P.D. Smith, R.F. Chuaqui, Z. Zhuang, S.R. Goldstein, R.A. Weiss, and L.A. Liotta. 1996. Laser capture microdissection. Science 274:998-1001.

3.Farrell, R.E., Jr. 1997. DNA amplification. Immunol. Invest. 26:3-7.

4.Krizman, D.B., R.F. Chuaqui, P.S. Meltzer, J.M. Trent, P.H. Duray, W.M. Linehan, L.A. Liotta, and M.R. Emmert-Buck. 1996 Construction of a representative cDNA library from prostatic intraepithelial neoplasia. Cancer Res. 56:5380-5383.

5.Li, X.M., Z.Y. Tang, L.X. Qin, J. Zhou, and H.C. Sun. 1999. Serum vascular endothelial growth factor is a predictor of invasion and metastasis in hepatocellular carcinoma. J. Exp. Clin. Cancer Res. 18:511-517.

6.Lucotte, G., G. Mercier, and A. Burckel. 1998. The use of nested RT-PCR of prostatespecific membrane antigen in blood cells: im plications for the detection of hematogenous neoplastic cells in patients with prostate adenocarcinoma. Mol. Cell. Probes 12:421-425.

7.Ogawa, O., M. Iinuma, K. Sato, R. Sasaki, N. Shimoda, S. Satoh, and T. Kato. 1999. Circulating prostate-specific antigen mRNA during radical prostatectomy in patients with localized prostate cancer: with special reference to neoadjuvant hormonal therapy. Urol. Res. 27:291-296.

8. Renneberg, H., A. Friedetzky, L. Konrad, R. Kurek, K. Weingartner, G. Wennemuth, U.W. Tunn, and G. Aumuller. 1999. Prostate-specific membrane antigen (PSM) is expressed in various human tissues: implication for the use of PSM reverse transcription polymerase chain reaction to detect hematogenous prostate cancer spread. Urol. Res. 27:2327.

9.Wang, C., M. Wadehra, B.C. Fisk, L. Goodglick, and J. Braun. 2001. Murine epithelial membrane protein 2, a 4-transmem brane protein that suppresses B-cell lym phoma tumorigenicity. Blood 97:3890-3895.

10.Wei, C., R.A. Willis, B.R. Tilton, R.J. Looney, E.M. Lord, R.K. Barth, and J.G. Frelinger. 1997. Tissue-specific expression of the human prostate-specific antigen gene in transgenic mice: implications for tolerance and immunotherapy. Proc. Natl. Acad. Sci. USA 94:6369-6374.

We thank Maria Avina for her help and expertise in laser-capture microdissection, the HTRC for their excellent service, Lynn Gordon and David Stempel for the RT-PCR experiments examining $\beta B 1$ crystallin expression, and Jacob Schatz for helpful discussion. This work was supported by California Cancer Research Program grant no. INIO117 to L.G. and a grant from the Lym phoma Research Foundation of America to J.B. Address correspondence to Dr. Lee Goodglick, UCLA Department of Pathology and Laboratory Medicine, 10833 Le Conte Avenue, Los Angeles, CA 90095-1732, USA. e-mail:lgoodglick@mednet.ucla.edu

Received 25 July 2001; accepted 6 November 2001.
Madhuri Wadehra, Jonathan
Braun, and Lee Goodglick
UCLA School of Medicine
Los Angeles, CA, USA

\section{T Vectors With} Endoglucanase A (celA) Gene for Direct Detection of PCR Clones

BioTechniques 32:248-252 (February 2002)

The dsDNA products obtained by PCR with Taq DNA polymerase usually contain a single $3^{\prime}$ unpaired dATP residue gratuitously added by the DNA polymerase to its product (3). Accordingly, $\mathrm{T}$ vectors containing single 3 '-terminal thymidine overhangs produced by enzymatic tailing or digestion, such as $X c m$ endonuclease, have been widely used to allow efficient cloning of PCR products $(1,8)$. In theory, $\mathrm{T}$ vectors should not give rise to nonrecombinant clones after transformations in which no PCR product has been inserted. However, such background clones are frequently encountered in real cloning situations so that the detection of the correct clones out of many transformants is very cumbersome and time consuming. In recent years, numerous $\mathrm{T}$ vector systems have been developed to identify fast and efficiently the PCR clones in which the $\beta$-galactosidase or GFP gene was included as a marker $(4,6)$.

Endoglucanase A (i.e., cellulase A or celA) is a member of the glycosyl hydrolase family (EC 3.2.1.4) that catalyzes the hydrolysis of glycosidic bonds in cellulose. A novel gene cloning system, the pCEL1 ${ }^{\mathrm{TM}}-\mathrm{Cel}-$ lomix ${ }^{\mathrm{TM}}$ kit developed by RNA, Inc. (Suwon, Korea), utilizes a celA gene isolated from Clostridium thermocellum as a marker (2). Cellulase expressed by the celA gene forms a white circle around the colony in agar plates containing a chromogenic substrate, Cellomix. If the celA gene is disrupted by an inserted DNA, then no circle forms around the colony because of the insertional inactivation of the gene.

Based on the pCEL1-Cellomix kit, we describe here the constructions of two new $\mathrm{T}$ vectors with the celA gene for a direct detection of PCR product clones. Both of these T vectors, pCELT1 and pCEL-T2, contain two $X \mathrm{cmI}$ sites in the middle of multiple cloning sites (MCSs) of the celA gene in frame. 